\title{
IMPACT OF SPIRITUAL INTELLIGENCE ON EMPLOYEE TASK PERFORMANCE AND OCB; MEDIATING ROLE OF SELF EFFICACY, MODERATING ROLE OF COLLECTIVIST CULTURE OF PAKISTAN
}

\author{
SHAZIA FAIZ KHAWAJA \\ Capital University of Science and Technology, Islamabad, Pakistan
}

\begin{abstract}
The current study aimed to explore the impact of spiritual intelligence in the task performance and $\mathrm{OCB}$, through the mediating mechanism of self efficacy and the moderating impact of collectivist culture on the said relationship. Three separate linear regression models were developed to investigate the hypotheses. The data were collected using survey method from 313 doctors, employed in both public and private sector hospitals. The findings of the study suggested that spiritual intelligence leads to the increased task performance and enhanced OCB among doctors, whereas, self efficacy partially mediates the relationship. Moreover, collectivism positively moderates the relationship of spiritual intelligence with performance and OCB. The study concludes by discussing limitations and providing future research directions.
\end{abstract}

\section{INTRODUCTION}

Spiritual intelligence influence employee performance and benefits organization and the society (Gani, Hashim \&Ismail 2010; Rani, Abidin \& Hamid 2013; Soebyakto 2012 \& Hashim 2011); it governs and guides individuals' actions in all possible ways (Roberston, 2007). The concept of spiritual intelligence has been studied before by researchers under the title of workplace spirituality (Malik, Naeem \& Ali 2011), spirituality at work (Hashim, 2012), spiritual intelligence (Othman et el. 2012; Rani, Abidin \& Hamid 2013) and spirituality (Robertson, 2007; Gani et al. 2010) with different facets. The growing interest of researchers in religiosity could be possible product of environmental changes as well as change in values on a global scale (Geh, 2009). According to Chin, Anantharaman and Tong (2011) spiritual intelligence is the set of abilities that individuals apply to enhance their daily functioning and well-being and it also increases their capacity to understand others at a higher level.

Self efficacy would be a possible outcome of spiritual intelligence. According to Adeyemo, Adeleye (2013), self-efficacy is one's belief in his or her ability to perform a specific behavior to achieve an outcome. Spiritual tendency along with self efficacy predicts positive outcomes (Duggleby, Cooper \& Penz, 2009), while the collective efficacy is more effective for group performance (Stajkovic \& Lee, 2009). Boglera \& Somech (2004); Jawahar et al (2008) and Speier \& Frese (1997) supported the idea that self efficacy predicts organizational citizenship behavior as well, as it affects both task and contextual performance. These include citizenship behaviors exhibited in the form of helping a colleague with a job related problem, to general psychological support or employees' contribution towards organization image building more commonly known as altruism, courtesy, conscientiousness and civic virtue (Bukhari, 2008). Malik, Naeem and Ali (2011) proposed spiritual intelligence as a predictor of OCB while Animasahun (2008) suggested that spiritual intelligence along with self efficacy can play its due role in critical organizational situations and enhance contextual performance.

An individual's expectations towards organization rely on mutual cooperation and collaboration of management and employees. According to Amiri, Pourheidari and Hoseini (2012) culture strongly affects employees' performance and their relationship with organization. Supportive organizational culture and behaviors exhibited by management affirm worker performance. Farh, Hackett and Liang (2007) found culture an influential factor. Triandis (2001) analyzed that in collectivists' cultures employees perform better and value mutual benefits. Previously moderating role of culture was acknowledged and appreciated by researchers i.e. Farh, Hackett \& Liang (2007).

The spillover theory (Staines, 1980) provides the theoretical support for this study as individuals do live in social structure which ensures interdependent lives specifically in collectivist Pakistani culture. Thus, the 
expressions of attitudes, actions, beliefs, and activities in one domain spill over their effects to other domains. Researchers complimented the existence of spiritual intelligence with a variety of benefits and consider it impossible to keep it aside in personal and professional transaction for survival (Gani et al, 2010; Rani et al., 2013; Axtel \& Parker 2003), as an individual's work and personal lives are naturally connected. Spiritual intelligence gives birth to doctors self efficacy along with their technical credibility, which ultimately compliments their task performance as well as their organizational citizenship behavior in collectivist culture (Axtel \& Parker, 2003; Duggleby et al., 2009; Jawahar et al., 2008; Animasahun, 2008). Amiri et al. (2012) highlighted that culture can create constraints or opportunities for individuals attitudes, behavior and actions in organizational settings, which ultimately moderate the existing relationships for discussion. In collectivist culture of Pakistan, doctors' norms, values and behavior are influenced by this phenomenon, which shows its effects on their outcomes; such as task performance and organizational citizenship behavior.

According to Bandura (2001), the essence for a human being is the extent of control over the nature and quality of one's life. There are number of factors that ensure conscious functional attitude of individuals and they ensure their existence in a broad network of social structural influences. There are transactions among them; there are products as well as producers of social systems. Social cognitive theory (Luszczynska \& Schwarzer, 2005) explains direct personal interactions among individuals, their reliance on others to secure desired outcomes, and collective activity exercised through socially coordinative and interdependent efforts. This compliments an individual's spiritual intelligence and perceived efficacy to exercise control over personal accomplishments, as well as collective growth. In addition to that the systematic layout of goal setting and its execution keeping in view the overall benefits for every stake holder in religious context ensures its strong credibility for the relationship of collectivism with this equation.

In recent years in Pakistan the focus of individual, as well as government, has been the health industry with its potential challenges. Limited literature is available where doctors' technical and spiritual competence has been accessed previously. Present study is going to access concept of spiritual intelligence as spiritual maturity in health industry of Pakistan, as the exhibition of spiritual maturity is quite obvious by doctors in contrast to their unchallengeable technical expertise. Spiritual intelligence creates self efficacy, which ultimately helps them in managing their task performance at respective jobs, but also help them in enhancing their organizational citizenship behavior i.e., their relation with colleagues, patients and others. The moderating role of collectivist culture in this relationship is also obvious.

Present study is the first of its kind as previous literature has studied spiritual intelligence with other variables and context but not with these variables and in Pakistani context. The study, therefore, aims at contributing into the existing literature theoretically as well as contextually.

\section{LITERATURE REVIEW}

\section{Spiritual intelligence with task performance and OCB}

Spiritual intelligence is the ninth dimension added by Gardner (1999) in his famous multiple intelligence theory (1983), concerned with the belief that there is an ultimate power that determines our destiny, which influences our attitudes and behaviors in order to achieve harmony and peace and God's blessings. It is also considered sixth dimension of personality. There must be an integration of spirituality at all levels and stages of human life to ensure survival and sustainability of humanity (Di, 2013) and companies (Srivastave \& Misra, 2012). Researchers strongly emphasized application of spiritual intelligence for peaceful and convenient life (Shah \& Elahi, 2012; Moodley, 2008; Burkhart, 2006). Gotsis and Kortezi (2008) considered it prerequisite for individual and organizational success (Hicks, 2002; 2003; 2005). Spirituality has close association with an individual's job and organizational activities (Kolodinsky, Giacalone \& JurkieuHcz, 2007). Javadi, Mehrabi, Jamkhaneh \& Samangooei (2012); Amram \& Dryer, (2007) found it affective for working individuals in organizational settings.

\section{Spiritual Intelligence Dimensions}

\section{i. Inner life}

According to Geh (2009), it is one's conception of his own divine power and how one uses it to live a more content life and bring his true personality to work, including his spiritual side. Ashmos and Duchons (2005), added that it reflects individual identity (a person's view about himself) as well as social identity (his social standing) of a person. Javanmard (2012) concluded that it is a combination of an individual's self identity as well as his attitude as a member of group or organization.

\section{ii. Meaningful work}

Individual's involvement in their work gives more meaning to their lives (Geh 2009). Javanmard (2012) 
and Ashmos \& Duchons (2005) explained it as doing something more than the concept of job design, simply makes it more significant. Amram (2007) \& Milliman et al. (2003) posited that in such a case, every activity is performed with a purpose.

\section{iii. Sense of community}

Individuals live their lives in connection to other human beings in the organization (Geh, 2009; Ashmos \& Duchons, 2005). Spirituality was found as central to Muslims' functioning (Patel \& Shikongo 2006). Emmon (2000) proposed spirituality as a form of intelligence, which consists of a set of capacities and abilities that enable people to solve their problems and attain their goals in their everyday lives. Ciarrochi, Liacco and Deneke (2008) added that religious practices and spiritual tendency give hope and optimism to individuals, which ultimately give meaning to their life. Othman et al. (2012) posited that it is a source of work life balance e. g., personal and professional life. Spiritual intelligence helps in solving specific problems but its application in every moment exhibits greater meaning to life (Amram, 2007; Amram \& Dryer, 2008).

Milliman, Czaplewski and Ferguson (2003) identified a positive association between spirituality at work and their job outcomes for individuals and organizations, which improve professional performance as well as strengthen their relationship with the organization. Hosseini, Elias, Krauss \& Aishah (2010) found significant influence of spirituality on individuals' vision, smooth functioning and adaptation, because it offers capabilities which predict its association with rational cognitive processes like goal achievement and problem resolution at both individual and organization level. Moodley (2008) posited that it improved behavior of individuals and made them beneficial members of society and organizations. Burkhart (2006) added that spirituality has been essential for effective growth and development of individuals and their task achievement. According to Javadi et al. (2012), these skills enhance their social relations and problem solving capabilities and improve their surrounding environments. Spiritual intelligence conduce the organizational environment, which ultimately ensures increased productivity. It also encourages employees to go beyond their responsibilities (Chin, Anantharaman \& Tong, 2011).

Walsh, King, Jones, Tookman, \& Blizard (2002) concluded that individuals' spiritual belief strength has been an important predictor of outcomes. Physicians have been using these spiritual beliefs for traumatic treatment along with medical care and found it affective; people suffered from grief and traumas resulted from unpleasant incidents recovered faster than those with no spiritual intelligence. Probst \& Strand (2010) appreciated the efficacy of spirituality and considered it a non-traditional but complementary method for treating disease, trauma, and other adverse life events by expert, but also found it effective for employees in job related challenges. Flinders \& Thoresen (2008) strongly recommended the incorporation of religion and spirituality in academic course content to make individuals aware of its importance. It not only supports and reinforces their assimilation of virtues and character strengths, but also a practical component to make them learn these skills and apply them in daily life. They specifically encouraged the adaptation of these strategies by physicians in treatment of different patients.

Individuals not only contribute for their tasks but also exert effort for the wellbeing of every individual around them including employees, customers, and society (Geh, 2009; Howard \& White, 2009). King and Williamson (2005) added that acceptance of religious expression at work settings by organizations and an individual is important because it has most significant influence on outcomes. Affeldt and MacDonald (2010) analyzed that effective exhibition of spiritual tendencies by health care professional brought significant association with their performance and organizational citizenship behavior.

On the basis of this literature review following hypotheses were developed:

\section{Hypothesis 1. Spiritual intelligence significantly and positively affects doctor's task performance}

\section{Hypothesis 2. Spiritual intelligence significantly and positively affects doctor's organizational citizenship behavior}

\section{Self efficacy as a mediator}

Self-efficacy is the belief in one's competence to tackle difficult or novel tasks and to cope with adversity in specific demanding situations. Self-efficacy makes a difference to how people feel, think, and act in a particular situation (Bandura, 1997). It is the ultimate self confidence of an individual in his capabilities in tasks performance beyond traditional boundaries (Axtel \& Parker 2003). Self efficacy is the formation of one behavior in defined domain, which enhances level of self sufficiency for goal achievement at individual and organizational level. Luszczynska, Don \& Schwarzer (2005) differentiated between general self efficacy and task related self efficacy. According to them general self-efficacy is an individuals' belief on his competence to tackle in stressful or challenging encounters; while specific self-efficacy is guarded to a particular task at hand. In context of individuals' personality, self efficacy 
can be observed in various forms, e.g. intellectual self efficacy, emotional self efficacy and volitional self efficacy are important representations of self efficacy. Maxwell (1997) highlighted that individuals with potential self efficacy influence their surroundings, they are aware of their capabilities, access self actualization, define their life accordingly and make efforts for the desired outcomes. Furthermore, he explained (2010) that self efficacy has been developed in individuals from childhood through respect and encouragement given to them by their parents and family, which is enhanced by others in later stages of life and enable individuals to show height of performance in every field.

Self efficacy is obvious with respect to job self efficacy, creative self efficacy, group self efficacy and team self efficacy, each dimension brings improvement in attitudes and behavior of employees, which enhance task performance and organizational citizenship behavior in organization. Gupta (2012) found strong correlation between spiritual intelligence and self efficacy. His findings suggested that males were more spiritually intelligent and self efficient. According to Tierney \& Farmer (2002), self efficacy strengthens employee belief on their potential and creativity, which in the end ensures performance beyond the expectations. Empirical research indicated a strong and consistent linkage of self-efficacy with productive outcomes. According to Prussia, Anderson \& Manz (1998), effective utilization of enhancing strategies improve self efficacy perceptions of employee and these positive perceptions of self-efficacy significantly ensured subsequent performance. Jawahar et al. (2008) added that self efficacy is strong predictor of employees' task performance. Luszczynska et al. (2005) added that individuals possessing high self efficacy prefer to perform more challenging tasks, set higher goals, stick to them and show high task performance. Similarly, Davis, Fedor, Parsons \& Herold (2000) believed that performance affects self efficacy. Gibson (2001) found a close relationship between self efficacy and effectiveness, specifically in health sector, those employees who possessed low self efficacy enhanced their level through training and their individual self efficacy in contrast to other individuals showed best group efficacy and increased performance in organizations.

According to Chen, Gully and Eden (2004) employees with belief of high self efficacy excel in organization, they realize their self worth in relation to their capabilities and their input increases their performance. Their findings suggested that general self efficacy along with specific self efficacy increased their self confidence towards organization and themselves.
Axtel \& Parker (2003) studied self efficacy and found it effective in organizational settings, while Duggleby et al. (2009) suggested that spiritual tendency of employees along with self efficacy gives positive outcomes. Lin, Baruch and Shih (2011) found self efficacy to be an effective mediator between other variables and performance. They added that various practices give birth to self efficacy and this output in relation to its input place speedy effects on outcomes like increased performance. Boglera (2004) observed positive influence of self efficacy on individual task performance as well as on organizational citizenship behavior.

In context of the above literature following hypotheses were developed:

\section{Hypothesis 3. Self efficacy mediates the relationship between spiritual intelligence and employee task performance}

\section{Hypothesis 4. Self efficacy mediates the relationship between spiritual intelligence and organizational citizenship behavior}

\section{Collectivism as a moderator}

Individuals define themselves in their cultural context, as values, beliefs and norms of a culture are learned by its individuals. Jurkiewicz and Giacalone (2004) suggested that there is a need to identify the moderating variables that could possibly affect the significant positive relationship of spiritual intelligence with the performance of individuals in organizations i.e. personal ethics, culture, etc. According to Moalosi (2012) in collectivist cultures individuals have a tendency towards group-orientation and hold more socially responsible attitude. Gómez, Kirkman and Shapiro (2000) found that in collectivist cultures employees are more cooperative and cohesive in their attitudes towards task performance and more committed, satisfied and trustful towards other organizational members and organizations. According to Moorman and Blakely (1995) when individuals exhibit collectivistic values or norms in work settings, they are more likely to perform citizenship behavior. They look for ways which are not related to their interest but are contributing to the welfare of the other members and organization. Employees with collectivistic orientation prefer to go beyond their task responsibilities and offer help, take initiative and exhibit organizational citizenship behavior at best. Euwema, Wendt and Emmerik (2007) examined that societal culture reflects national culture, which significantly affects organizational citizenship behavior of groups. Culture was found an affective moderating variable for 
the study. Wimsatt and Gassenheimer (2000); Erdogan and Liden (2006) also highlighted the role of collectivism as moderator among various variables. Gibson (1999) identified close relationship of this cultural dimension with the performance of employees. Chen, Chen and Meindl (1998) identified that cooperation, trust, accountability, communication; goal sharing, structure of rewards and incentives are core features of collectivist culture, which significantly affect the outcomes.

Earley (1993) strongly recommended the understanding of context for analysis of employees' performance. According to him individualist approach could not work in group context, while collectivistic approach seemed inappropriate in individual pro work environment. Furthermore, the behaviors are shaped and approved by members who in contrast strongly affect performance, while Man and Lam (2003) found different strategies with effective, prominent and promising outcomes in individualistic rather than in collectivistic teams.

Therefore, the following hypotheses are developed:

Hypothesis 5. Collectivism positively moderates the relationship between spiritual intelligence and employee performance

Hypothesis 6. Collectivism positively moderates the relationship between spiritual intelligence and organizational citizenship behavior.

\section{THEORETICAL FRAMEWORK}

FIGURE 1

Conceptual framework for the study

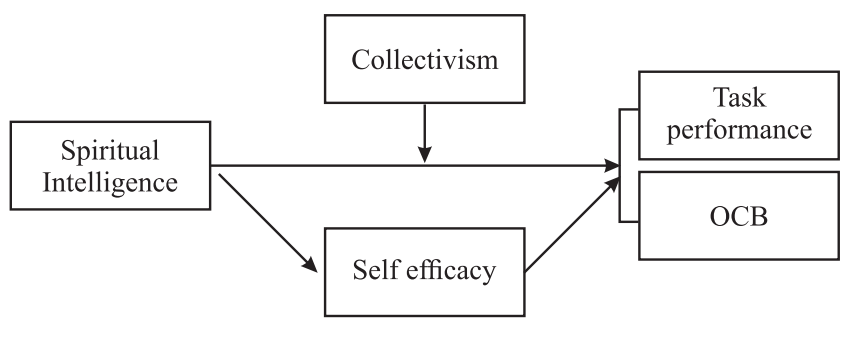

\section{RESEARCH METHODOLOGY}

\section{Sampling procedure and population}

The current study is a cross sectional study, where unit of analysis is an individual. Health sector is focused for the exploratory study, whereas the sample size for the study is 400 and population consisted of doctors holding different positions. According to PMDC (2013) there are around 132,988 registered doctors in Pakistan, and 53,252 registered MBBS doctors only in Punjab and Federal area, out of which 28,721 are male while 24,531 are female doctors. Non-probability, snowball sampling technique was used to draw the sample; initially family doctors were contacted and asked for their cooperation, and later hospitals were visited with their reference for data collection.

Out of 400 questionnaires 313 were received back with a response rate of $78 \%$. The respondents were dominated by males with $57 \%$, while female respondents were about $42 \%$, out of which $31 \%$ were single and $68 \%$ were married. $3 \%$ respondents were between 25 to 30 years old, $33 \%$ respondents were between 31 to 35 years old, 36\% respondents were aged between 36-40 years, while about $29 \%$ respondents were between 41 to 50 years old. Most of the respondents were MBBS $(47 \%)$, while $31 \%$ were FCPS medicine specialized and $21 \%$ were FCPS surgeon. Majority of respondents were medical officers in their respective hospitals, while $19 \%$ were senior medical officers and $20 \%$ were additional medical officers; only $11 \%$ of the respondents were principal medical officers. $21 \%$ of the doctors had more than 10 years of experience.

\section{Instrumentation}

The data were collected using survey method. Already developed questionnaires were adopted for each variable. The validated measures for the spirituality scale developed by Ashmos and Duchon (2005) was used; first 9 questions were about the doctors dealing with their community, further 7 question were about task achievement and meaning at work and last five questions were reflection of their personal attitude, self and inner life; how they consider their progress in life in that scenario. To access doctors' self efficacy, perceived general self efficacy scale of Schwarzer \& Jerusalem, (1995) used by Zarrafshani et al. (2008), for collectivism scale developed by Gaines, Marelich \& Bledsoe, (1997) was used; for task performance Becker \& Kernan (2003) scale used by Tuttle, Matthew D, (2009) was adopted. For OCB a scale developed by MacKenzie et al. (1994) was used; where first two questions were about altruism, next five about conscientiousness and last three questions were about civic virtue. All instruments were converted into 5-point Likert scale where " $1=$ strongly disagree" and " $5=$ strongly agree" to maintain the clarity for the respondent.

\section{RESULTS}

Table (1) shows the results of correlation analysis, along with the Cronbach's Alpha values of each variable in parenthesis, to show the reliability of the scales adopted. 
TABLE 1

Correlation Analysis

\begin{tabular}{lllllllll}
\hline S\# & Variable & Mean & S.D. & $\mathbf{1}$ & $\mathbf{2}$ & $\mathbf{3}$ & $\mathbf{4}$ & $\mathbf{5}$ \\
\hline 1 & Spiritual Intelligence & 4.41 & 0.29 & $(.812)$ & & & & \\
2 & Self efficacy & 4.52 & 0.33 & $.406^{* *}$ & $(.799)$ & & & \\
3 & Collectivism & 4.45 & 0.35 & $.302 * *$ & $.203 * *$ & $(.771)$ & & \\
4 & Task performance & 4.46 & 0.39 & $.411 * *$ & $.253^{* *}$ & -.040 & $(.805)$ & \\
5 & OCB & 4.42 & 0.38 & $.213 * *$ & $.204 * *$ & $.157 * *$ & .066 & $(.867)$ \\
\hline$* * * p<.001, * * p<.005, * p<.01$ & & & & & &
\end{tabular}

TABLE 2

Regression Analysis for outcomes

\begin{tabular}{lcccccc}
\hline Predictors & \multicolumn{3}{c}{ Task Performance } & \multicolumn{3}{c}{ OCB } \\
& $\boldsymbol{\beta}$ & $\mathbf{R}^{\mathbf{2}}$ & $\Delta \mathbf{R}^{\mathbf{2}}$ & $\boldsymbol{\beta}$ & $\mathbf{R}^{\mathbf{2}}$ & $\Delta \mathbf{R}^{\mathbf{2}}$ \\
\hline $\begin{array}{l}\text { Step I } \\
\text { Control Variables }\end{array}$ & & & & .010 & \\
Step II & .022 & & & \\
Spiritual intelligence & $.551^{* * *}$ & .187 & $.165^{* * *}$ & .285 & .056 & .046 \\
\hline
\end{tabular}

Dependent variables: Task performance, OCB, ***p<.001

Table (1) is the Pearson correlation analysis which indicates the nature of relationship among the variables, how these variables associated with each other and Cronbach's alphavalues for reliabilities. Meanand standard deviation values of all variables are also given. The tables indicates that Spiritual intelligence has a significant and positive correlation with doctor's Task performance with a value of $.411^{* *}$ or about $41 \%$, while with OCB $.213^{* *}$ or $21 \%$ association. The positive relationship shows that these variables have direct relationship between them i.e. increased spiritual intelligence attitude by doctors would increase their task performance as well as their organizational citizenship behavior. The correlation table also indicates that their task performance has negative relationship with collectivism with a correlation value of -.040 as the negative sign with the value indicates an inverse relationship i.e. the more doctors' concerned with collective benefits they would have a lesser concern with their individual tasks and vice versa. Rests of the variables have significant positive relationship among them. The value $.406^{* *}$ shows that the strength of association of $40 \%$ between these variables and has a direct relationship i.e. greater the doctor's spiritual intelligence, greater will be his level of self efficacy, while for collective benefits the value is $.302 * *$ or $30 \%$.

All hypotheses were tested through separate regression analyses using Barron and Kenny (1986) method, to find empirical evidence for the assumptions. Table (2) shows the results of the regression analysis for outcomes. In Step 1 demographic variables like gender, marital status, qualification, etc were controlled to scratch their influence from the analysis, which represented a value of $\mathrm{R}^{2} .022$. In step 2, spiritual intelligence was regressed on task performance and $\mathrm{OCB}$, which showed the relationship to be significant at $\beta=.551, \mathrm{t}(7.870), \mathrm{p}$ $=.000$, and $\beta=.285, \mathrm{t}(3.840), \mathrm{p}=.000$ respectively, with overall fitness of the model, $\mathrm{F}=10.042, \mathrm{p}=.000$ and $2.587, \mathrm{p}=.013$.

TABLE 3

Mediated Regression Analysis

\begin{tabular}{|c|c|c|c|c|c|c|}
\hline \multirow[t]{2}{*}{ Predictors } & \multicolumn{3}{|c|}{ Task Performance } & \multicolumn{3}{|c|}{ OCB } \\
\hline & $\boldsymbol{\beta}$ & $\mathbf{R}^{2}$ & $\Delta \mathbf{R}^{2}$ & $\beta$ & $\mathbf{R}^{2}$ & $\Delta \mathbf{R}^{2}$ \\
\hline \multicolumn{7}{|l|}{ Step I } \\
\hline Control Variables & & .022 & & & .010 & \\
\hline \multicolumn{7}{|l|}{ Step II } \\
\hline Self efficacy & $.288 * *$ & .083 & .060 & $.246 * * *$ & .056 & .046 \\
\hline \multicolumn{7}{|l|}{ Step III \& IV } \\
\hline Spiritual intelligence & $.499 * * *$ & .195 & .112 & $.202 * *$ & .075 & .019 \\
\hline
\end{tabular}

$I V=$ Spiritual intelligence, Mediator $=$ self efficacy, $D V=$ Task performance \& $O C B$ 
TABLE 4

Moderated Regression Analysis

\begin{tabular}{|c|c|c|c|c|c|c|}
\hline \multirow[t]{2}{*}{ Predictors } & \multicolumn{3}{|c|}{ Task Performance } & \multicolumn{3}{|c|}{ OCB } \\
\hline & $\boldsymbol{\beta}$ & $\mathbf{R}^{2}$ & $\Delta \mathbf{R}^{2}$ & $\boldsymbol{\beta}$ & $\mathbf{R}^{2}$ & $\Delta \mathbf{R}^{2}$ \\
\hline \multicolumn{7}{|l|}{ Step I } \\
\hline Control Variables & & .022 & & & .010 & \\
\hline \multicolumn{7}{|l|}{ Step II } \\
\hline Spiritual Intelligence & $.624 * * *$ & & & $.247 * *$ & & \\
\hline Collectivism & $-.201 * * *$ & .217 & .195 & $.105 *$ & .064 & .054 \\
\hline \multicolumn{7}{|l|}{ Step III } \\
\hline Spiritual Intelligence $\times$ Collectivism & $.581 * * *$ & .246 & .029 & $-.421 * *$ & .080 & .016 \\
\hline
\end{tabular}

Dependent variables $=$ task performance \& $O C B, * * * p<.0011,{ }^{*} p<.05$

The $\mathrm{R}^{2}$ value .187 showed that about $18 \%$ of association between doctors' task performance and their spiritual intelligence, while in case of OCB the value of $\mathrm{R}^{2}=.056$ showed $5 \%$ of association between spiritual intelligence capabilities and OCB. The $\beta$ values showed that the $55 \%$ variation in task performance was caused by spiritual intelligence, while for OCB the sensitivity score was $28 \%$. Thus, hypothesis hypotheses one and two were fully supported.

According to the hypotheses three and four, the above mentioned direct association is mediated by self efficacy. It is a specified given cause that works indirectly through a more direct cause to a final effect. Self efficacy adds to the overall variance accounted for in the model and explains how the direct relationship works. Based on a theoretical model, it was proposed that spiritual intelligence in doctors indirectly affects their task performance and OCB through the mediating cause of a general self efficacy.

The value of $\mathrm{R}^{2}=.022$ and 010 in first step represent value of controlled demographic variables. Step 2 of the mediation model shows that the mediator controlling for the scores, is significant with $\beta=.288$, $\mathrm{t}=4.475, \mathrm{p}=.000 \& \mathrm{~F}=3.919$ at .000 level for task performance, while for OCB beta value is $\beta=.246, \mathrm{t}=$ $3.834, p=.000, F=2.580$ with $p=.013$. Step $3 \& 4$ of the analyses revealed that, controlling for the mediator self efficacy, scores were still significant predictor of task performance and OCB with $\beta=.499, \mathrm{t}=6.502$, $\mathrm{p}$ $=.000$, while $\mathrm{F}$ stat is 9.177 for task, similarly, $\beta=.202$, $\mathrm{t}=2.496, \mathrm{p}=.013$, while $\mathrm{F}$ stat is 3.015 with $\mathrm{p}=.002$ for OCB, indicating partial mediation. Therefore, self efficacy partially mediates the relationship between spiritual intelligence and the doctor's task performance and OCB. This states that enhanced general self efficacy of doctors could account for a significant amount of variance in the relationship between potential use of spiritual intelligence to their improved task performance and OCB. The model predicted that higher the doctor's elf efficacy higher will be their task performance and

\section{OCB.}

Table (3) shows the results of the moderated regression analysis, to see whether collectivism moderated the relationship between use of Spiritual intelligence and Task performance \& OCB. The overall model was significant, $F=10.996, p=.000$. In first step value of controlled demographics represents $\mathrm{R}^{2}$ value of 0.02 . Next, the spiritual intelligence and culture were entered to find their score in the analysis and found $\mathrm{R}^{2}$ at $.217, \Delta \mathrm{R}^{2}=.195$, F stat $=10.531, \mathrm{p}=.000$; while $\beta$ $=.624$ for spiritual intelligence and for collectivism $\beta=-.201$. The value of $\mathrm{R}^{2}=.217$ of collectivism shows strength of relationship among these variables is about $25 \%$, while in case of OCB the sensitivity of relationship score remained $6 \%$. And in the final step, an interaction term between spiritual intelligence scores and collectivism scores shows that it is accounted for a significant proportion of the variance in total scores with $\beta=.581, \mathrm{R}^{2}=.246, \Delta \mathrm{R}^{2}=.029 \mathrm{p}=.001$.

The value of $\mathrm{R}^{2}$ at .246 shows the relationship when in contrast with spiritual intelligence for task performance. $\Delta \mathrm{R}^{2}=.029$ shows that change in original $\mathrm{R}$ square is about $2 \%$.

In case of OCB the results showed that it was accounted for a significant proportion of the variance in total scores with control variable $\mathrm{R}^{2}=.010, \beta$ of spiritual intelligence $=.247, \mathrm{p}=.00$ and for collectivism $\beta=.105, R^{2}=.064, \Delta R^{2}=.054$. The interactional term showed $\beta=.421, \mathrm{R}^{2}=.080, \Delta \mathrm{R}^{2}=.016$. The current model was consistent with the hypotheses five and six that collectivist culture of Pakistan positively moderates the relationship between spiritual intelligence and doctors' task performance, as well as between spiritual intelligence and OCB. Thus, the high collectivism scores indicated an increased potential of spiritual intelligence, which is complementing their task performance as well as OCB. Therefore, the existence of spiritual intelligence and a collectivist tendency in Pakistani doctors significantly enhances their task performance as well as OCB. 


\section{DISCUSSION}

This study was conducted to uncover the expression of spiritual intelligence exercised by individual doctors at their duties. The results indicated that task performance and OCB are explained by spiritual intelligence and there is positive relationship between doctor's spiritual intelligence and their task performance. The results are consistent with previous studies (Hanafai, 2010), where same relationship was found affective. Positive relationship was found between spiritual intelligence and OCB; results are aligned with Geh (2009) findings. Values also reflect that self efficacy is the possible outcome of spiritual intelligence, which further affects doctors' task performance and their OCB. Spiritual intelligence optimized doctors' self efficacy capability; feelings of self sufficiency and self reliance not only improved their task performance but also enhanced their role of civic virtue, their potential of conscientiousness and affectivity in form of altruism. The empirical results support the hypotheses and also showed that culture significantly moderates the relationship between spiritual intelligence and task performance in a positive way. While, in case of relationship between spiritual intelligence and $\mathrm{OCB}$, collectivist culture has mixed influence, whereas, with contrast of spiritual intelligence its combined effect remained positive.

Based on Barron and Kenny (1986) method, it has been empirically proven that the relationship between spiritual intelligence and task performance, as well as OCB is significant and stronger as indirect relationship; although, self efficacy does partially mediate the relationship. Because the path analysis showed that it remained affective till third step and could not worked at last step, thus the mediating hypotheses three and four were partially accepted. The overall results indicate that the hypothesized model has achieved model fitness and the hypotheses were supported.

The empirical findings also proved that doctors in Pakistan willingly exhibit high level of spiritual intelligence, which is an expression of their spiritual maturity at individual and organizational level. Furthermore, the findings proved that self efficacy is not the only product of spiritual intelligence; there are multiple outcomes of this single phenomenon. Thus, self efficacy could not fully mediate this relationship. In addition, findings also suggest that due to increased influence of globalization and media, Pakistani society is moving from collectivistic culture to individualistic culture, the mixed expression of attitude.

Culture plays a significant role among existing relationships. In case of task performance, collectivism has a negative impact while in existence of spiritual intelligence, whereas combined effect remained positive and employees also focused on their task. However, in case of the relationship between spiritual intelligence and $\mathrm{OCB}$, collectivism played a positive role, but on the other hand, with spiritual intelligence the negative sign showed that freedom of expression and individual spiritual tendencies are now influenced by culture. Media has reduced its spiritual extreme expression and now moderated level spiritual expression forces individuals for a bounded expression of OCB.

The present study seems to be a possible extension of Hashim's (2013) work on spirituality in which he specifically recommended that spirituality must be studied with OCB in different culture to find out its role. Essentially, in Pakistan doctors consider themselves morally obliged to work for the welfare of their countrymen and help them to reduce their sufferings, they posses spiritual intelligence and express their inner self, their sense of community, emphasis on meaningful work from their side and show improved individuals task performance as well as OCB for collective benefits. The findings of this study also compliment the the Ashmos and Duchons (2005) findings with similar construct. In specific culture, individual values and attitudes are shaped by their spiritual beliefs. Use of spiritual intelligence reflects their spiritual maturity in changing scenarios where situations are unpredictable for both the doctors and their patients. In chaos or certainty, a doctor's self efficacy along with his technical expertise is believed to have an important impact on many attitudes and behaviors. It not only makes him/her a better performer in this job, but also an excellent member of his organization and a better citizen of his country as well. This sense of responsibility and self reliance brings maturity in their actions and proceedings.

\section{CONCLUSION}

Religiosity and spirituality are undeniable and significant parts of every individual's personality in Pakistan. Their inner self moves along with actual work activities and makes their job meaningful, while welfare of the community is their ultimate choice with vigorous actions. This religious and spiritual dimension remained dominant for decades. The enhanced collectivism has numerous benefits; now mixed culture is also being experienced by countrymen with both individualistic and collectivistic tendencies. Furthermore, spiritual intelligence enhances self efficacy, which further influences task performance and $\mathrm{OCB}$, while collectivist culture significantly performs its due role.

The results of this research have important implications and limitations. The findings imply that doctors as employees express spiritual maturity and self efficacy and this self efficacy is responsible for 
their improved task performance and OCB. Moreover, the collectivist culture discourages focus on individual benefits and promotes collective welfare. Results proved that Pakistani doctors are concerned with their OCB as well as their individual task but increased emphasis on moderate expression of religiosity and spirituality bounds them to exhibit controlled attitude and behavior. Secondly, there is shift in culture from collectivist to individualist thus it also emphasizes on bounded expression of spiritual maturity for OCB to maintain a balance in a country, where people of different religions and spiritual tendencies have equal rights and freedom of expression. There is a need to further study the role of mix culture in country and assess its multiple dimensions.

As scores come up with variation as expected by the researcher, the study may also have implications for other researchers, practitioners, and scholars in health sector. The findings of this study may provide hospitals' management with a rationale for designing and implementing programs for spiritual grooming so that they may find ways to enhance doctors' spiritual capabilities. It is important to notify that the contextual and cultural factors which have influence on spiritual expression are different in different organizations.

\section{Limitations}

The study has few limitations, although the sample size was large enough to generalize assumptions and findings to other work settings, yet results need to be interpreted with caution. Secondly, application of the measures originally designed in other cultures to the Pakistani sample is debatable because of variation in perceptions and conceptions make difference, despite having sufficient reliabilities and acceptable model fitness. Pakistani doctors have their own and unique perceptions and application of spiritual intelligence that are for sure different from those constructed in the Western and other cultures to some extent. Thirdly, the respondent filled questionnaire on the basis of their perception and understanding about them, there is chance of error.

\section{Recommendations}

After the extensive work the researcher has few recommendations. Firstly, the spiritual intelligence or spiritual maturity must be expressed by the doctors with positive expectations to enhance task as well as OCB. Secondly, training programs need to be organized by hospitals for both doctors and patients, to ensure its real existence and implementations.

\section{Future Research Directions}

For future researches the researchers need to assess effects of spiritual intelligence in relation with other variables, like impression management and integrity in Pakistani culture. It would produce more interesting results across cultures. There is a strong need of spiritual maturity by individuals in organizations; assignments can be given to policy makers, practitioners and future researchers to work on this issue. The study can also be episodic and longitudinal to get better results and confirm maturity and progress of behavioral changes.

At the end the author is strongly in favor of spiritual intelligence expression by doctors and other professionals for positive outstanding outcomes as in Pakistani context religion and spirituality are dominant factors, people are spiritually mature but there is strong need to differentiate between these two keeping in mind that there is no alternative for spirituality.

\section{REFERENCES}

Adeyemo, D. A., \& Adeleye, A. T. (2008). Emotional intelligence, religiosity and self-efficacy as predictors of psychological well-being among secondary school adolescents in Ogbomoso, Nigeria. Europe's Journal of Psychology,4(1).

Affeldt, D. L., MacDonald, D. A. (2010). The relationship of spirituality to work and organizational attitudes and behaviors, In a sample of employees from a health Care system. The Journal of Transpersonal Psychology, 42(2), 192-208.

Amram, Y. (2007). Paper presented at the 115th Annual Conference of the American Psychological Association San Francisco, CA.

Amram, Y., \& Dryer, D. C. (2008). Paper Presented at the 116th Annual Conference of the American Psychological Association Boston, MA.

Ashmos, D. P., \& Duchon, D. (2000). Spirituality at work: A conceptualization and measure. Journal of Management Inquiry, 9(2), 134-145.

Axtell, C. M., \& Parker, S. K. (2003). Promoting role breadth self-efficacy through involvement, work redesign and training. Human Relations, 56(1), 113-131.

Bandura, A. (1997). Self-efficacy: The exercise of control. New York: Freeman.

Bandura, A. (2001). Social cognitive theory: An agentic perspective. Annual Review of Psychology, 52(1), $1-26$.

Baron, R. M., \& Kenny, D. A. (1986). The moderator-mediator variable distinction in social psychological research: Conceptual, strategic, and statistical considerations. Journal of Personality and Social Psychology,51(6), 1173-1182. 
Becker, T. E., \& Kernan, M. C. (2003). Matching commitment to supervisors and organizations to in-role and extra-role performance. Human Performance, 16(4), 327-348.

Bogler, R., \& Somech, A. (2004). Influence of teacher empowerment on teachers' organizational commitment, professional commitment and organizational citizenship behavior in schools. Teaching and Teacher Education, 20(3), 277-289.

Bogler, R., \& Somech, A. (2004). Influence of teacher empowerment on teachers' organizational commitment, professional commitment and organizational citizenship behavior in schools. Teaching and Teacher Education, 20(3), 277-289.

Burkhart, H. V. (2006). The Interaction Effect of Spirituality and Negative Life Experiences on Depression. Master's Theses, Dissertations and Graduate Research Overview. Paper 31.

Chen, C. C., Chen, X. P. \& Meindl, J. R. (1998). How Can Cooperation Be Fostered? The Cultural Effects of Individualism-Collectivism. The Academyof Management Review, 23(2), 285-304.

Chen, G., Gully, S. M. \& Eden, D. (2004). General Self-Efficacy and Self-Esteem: Toward Theoretical and Empirical Distinction between Correlated SelfEvaluations. Journal of Organizational Behavior, 25(3), 375-395.

Chin, S. T. S., Anantharaman, R. N., \& Tong, D. Y. K. (2011). The roles of emotional intelligence and spiritual intelligence at the workplace. Journal of Human Resources Management Research, 2011, 1-9.

Ciarrocchi, J. W., Dy-Liacco, G. S., \& Deneke, E. (2008). Gods or rituals? Relational faith, spiritual discontent, and religious practices as predictors of hope and optimism. The Journal of Positive Psychology, 3(2), 120-136.

Davis, W. D., Fedor, D. B., Parsons, C. K., \& HeroldSource D. M. (2000). The Development of Self-Efficacy during Aviation Training. Journal of Organizational Behavior, 21(8), 857- 871.

Duchon, D., \& Plowman, D. A. (2005). Nurturing the spirit at work: Impact on work unit performance. The Leadership Quarterly, 16(5), 807-833.

Duggleby, W., Cooper, D., \& Penz, K. (2009). Hope, self-efficacy, spiritual well-being and job satisfaction. Journal of Advanced Nursing, 65(11), 2376-2385.

Earley, P. C. (1993). East Meets West Meets Mideast: Further Explorations of Collectivistic and Individualistic Work Groups. The Academy of Management Journal, 36(2), 319-348.

Emmons, R. A. (2000). Is spirituality an intelligence? Motivation, cognition, and the psychology of ultimate concern. The International Journal for the Psychology of Religion, 10(1), 3-26.
Erdogan, B., \& Liden, R. C. (2006). Collectivism as a Moderator of Responses to Organizational Justice: Implications for Leader-Member Exchange and Ingratiation. Journal of Organizational Behavior, 27(1), $1-17$.

Euwema, M. C., Wendt, H., \& Emmerik, H. V. (2007). Leadership Styles and Group Organizational Citizenship Behavior across Cultures. Journal of Organizational Behavior, 28(8), 1035-1057.

Farh, J. L., Hackett, R. D., \& Liang, J. (2007). Individual-level cultural values as moderators of perceived organizational support-employee outcome relationships in China: Comparing the effects of power distance and traditionality. Academy of Management Journal, 50(3), 715-729.

Gaines Jr, S. O., Marelich, W. D., Bledsoe, K. L., Steers, W. N., Henderson, M. C., Granrose, C. S., ... \& Yum, N. (1997). Links between race/ethnicity and cultural values as mediated by racial/ethnic identity and moderated by gender. Journal of Personality and Social Psychology, 72(6), 1460-1476.

Gardner, H. (1983). Frames of mind: The theory of multiple intelligences. New York: Basic Books.

Gardner, H. (1993). Multiple intelligences: The theory in practice. New York: Basic Books.

Gardner, H. (1999). Intelligence reframed: Multiple intelligences for the 21st century. New York: Basic Books.

Geh, Z. Y. E. (2009). A study of the effects of mediators between spirituality at work and organizational citizenship behaviors.

Gibson, C. B. (1999). Do They Do What They Believe They Can? Group Efficacy and Group Effectiveness across Tasks and Cultures. The Academy of Management Journal, 42(2), 138-152.

Gibson, C. B. (2001) Me and Us: Differential Relationships among Goal-Setting Training, Efficacy and Effectiveness at the Individual and Team Level. Journal of Organizational Behavior, 22(7), 789-808.

Gómez, C., Kirkman, B. L., \& Shapiro, D. L. The Impact of Collectivism and In-Group/Out- Group Membership on the Evaluation Generosity of Team Members. The Academy of Management Journal, 43(6), 1097-1106.

Gotsis, G., \& Kortezi, Z. (2008). Philosophical Foundations of Workplace Spirituality: A Critical Approach. Journal of Business Ethics, 78(4), 575-600.

Gotsis.G., and Kortezi, Z. (2008). Philosophical Foundations of Workplace Spirituality: A Critical Approach. Jorrnal of Business Ethics, 78(4), 575-600.

Gupta, G. (2012). Spiritual intelligence and emotional intelligence in relation to self-efficacy and self-regulation among college students. Int J Social Sci Interdisciplinary Res, 1(2), 60-9. 
Hashim, J. (2013). Spirituality, integrity and counterproductive work behaviours among employees of selected Islamic organisations in Malaysia, 14-16.

Hosseini, M., Elias, H., Krauss, S. E., \& Aishah, S. (2010).Areviewstudy on spiritualintelligence, adolescence and spiritual intelligence, factors that may contribute to individual differences in spiritual intelligence, and the related theories. International Journal of Psychological Studies, 2(2), 179-188.

Howard, B. B., Guramatunhu-Mudiwa, P., \& White, S. R. (2009). Spiritual intelligence and transformational leadership: A new theoretical framework. Journal of Curriculum and Instruction, 3(2), 54-67.

Javadi, M. H. M., Mehrabi, J., Jamkhaneh, H. B., \&Samangooei, B. (2012) Studying the Impact of Emotional Intelligence and Spiritual Intelligence on Organizational Entrepreneurship. Australian Journal of Basic and Applied Sciences, 6(9), 378-384.

Javanmard, H. (2012). The impact of spirituality on work performance. Indian Journal of Science and Technology, 5(1), 1961-1966.

Jawahar, I. M., Meurs, J. A., Ferris, G. R., \& Hochwarter, W. A. (2008). Self-efficacy and political skill as comparative predictors of task and contextual performance: A two-study constructive replication. Human Performance,21(2), 138-157.

Jurkiewicz, C. L., \& Giacalone, R. A. (2004). A Values Framework for Measuring the Impact of Workplace Spirituality on Organizational Performance. Journal of Business Ethics, 49(2), 129-142.

Khirzan, A. K. B. O. M., Rahman, B., Malik, A. M. A., \& Wahab, S. (2012). THE INFLUENCE OF MULTIPLE INTELLIGENCE ON CAREER ORIENTATION: THE VALIDATION OF HAMBA MULTIPLE INTELLIGENCE SCALE. Bilgi Ekonomisi ve Yönetimi Dergisi, 7(2), 1-15.

King, J. E., \&. Williamson, I. O. (2005). Workplace Religious Expression, Religiosity and Job Satisfaction: Clarifying a Relationship. Journal of Management, Spirituality \& Religion, 2(2), 173-198.

Kolodinsky, R. W., Giacalone, R. A., \& Jurkiewicz, C. L. (2008). Workplace Values and Outcomes: Exploring Personal, Organizational, and Interactive Workplace Spirituality. Journal of Business Ethics, 81(2), 465-480.

Krejsler, J. B. (2013). What works in education and social welfare? A mapping of the evidence discourse and reflections upon consequences for professionals. Scandinavian Journal of Educational Research, 57(1), 16-32.

Lin, C. P., Baruch, Y., \& Shih, W. C. (2012). Corporate social responsibility and team performance: The mediating role of team efficacy and team self-esteem. Journal of Business Ethics, 108(2), 167-180.

Luszczynska, A., rrez-Doña, B. G. \& Schwarzer,
R. (2005). International Journal of Psychology, 40(2), 80-89.

Luszczynska, A., \& Schwarzer, R. (2005). Social cognitive theory. Predicting Health Behaviour, 2, 127169.

Malik, M. E., Naeem, B., \& Ali, B. B. (2011). Sales Force Organizational Citizenship Behavior: Role of Meaning at work and Conditions for Community. Interdisciplinary Journal of Contemporary Research In Business, 3(8), 654-666.

Man, D. C., \& Lam, S. S. K. (2003). The Effects of Job Complexity and Autonomy on Cohesiveness in Collectivistic and Individualistic Work Groups: A CrossCultural Analysis. Journal of Organizational Behavior, 24(8), 979-1001.

Maxwell, E. (1998). "I can do it myself!" Reflections on early self-efficacy. Roeper Review, 20(3), 183-187.

Milliman, J., Czaplewski, A. J., \& Ferguson, J. (2003). Workplace spirituality and employee work attitudes: An exploratory empirical assessment. Journal of Organizational Change Management, 16(4), 426-447.

Moalosi, W. T. S. (2012). Cultural Concepts of Learning and Development. International Journal of Scientific Research in Education, 5(4), 287-291.

Moodley, T. (2008). The relationship between coping and spiritual well-being during adolescence. Dissertation submitted to University of the Free State, Bloemfontein.

Moorman, R. H., Blakely, G. L. (1995) IndividualismCollectivism as an Individual Difference Predictor of Organizational Citizenship Behavior. Journal of Organizational Behavior, 16(2), 127-142.

Mosley, D. C. Jr., Boyar, S. L., Carson, C. M., \& Pearson, A. W. (2008). A Production Self- efficacy Scale: An Exploratory Study. Journal of Managerial Issues, 20(2), 272-285.

Oman, D., Flinders, T., \& Thoresen, C. E. (2008). Integrating spiritual modeling into education: A college course for stress management and spiritual growth. The International Journal for the Psychology of Religion,18(2), 79-107.

Osman-Gani, A. M., Hashim, J., \& Ismail, Y. (2010). Effects of religiosity, spirituality, and personal values on employee performance: A Conceptual Analysis, 11-14.

Patel, C. J., \& Shikongo, A. E. E. (2006). Handling Spirituality/ReligioninProfessional Training: Experiences of a Sample of MuslimPsychology Students. Journal of Religion and Health, 45(1), 93-112.

Probst, T. M., \& Strand, P. (2010). Perceiving and responding to job insecurity: a workplace spirituality perspective. Journal of Management, Spirituality \& Religion, 7(2), 135-156.

Prussia, G. E., Anderson, J. S., \& Manz, C. C. (1998). Self-leadership and performance outcomes: The mediating influence of self-efficacy. Journal of Organizational 
Behavior, 19(5), 523-538.

Rani, A. A., Abidin, I., \& Hamid, M. R. (2013). The impact of spiritual intelligence on work performance: Case studies in government hospitals of east coast of Malaysia. The Macrotheme Review, 2(3), 46-59.

Robertson, L. H. (2007). Reflections on the Use of Spirituality to Privilege Religion in Scientific Discourse:Incorporating Considerations of Self Source. Journal of Religion and Health, 46(3), 449-461.

Shah, T., \& Ellahi, A. (2012). 2nd international conference on management (2nd icm 2012) proceeding 11th - 12th june 2012. Holiday villa beach resort \& spa, langkawi kedah, malaysia.

Shapiro, S. L., Oman, D., Thoresen, C. E., Plante, T. G., \& Flinders, T. (2008). Cultivating mindfulness: effects on well-being. Journal of Clinical Psychology, 64(7), 840-862.

Soebyakto, B. B., \& Ming, C. W. (2012). An empirical testing of intelligence, emotional and spiritual quotients quality of managers using structural equation modeling. International Journal of Independent Research and Studies, 1(1), 1-12.

Speier, C., \& Frese, M. (1997). Generalized self efficacy as a mediator and moderator between control and complexity at work and personal initiative: a longnitudinal field study in east Germany. Human Performance, 10(2), 171-192

Srivastava, A., \& Misra, S. (2012). Is Spiritual Quotient a better tool of success: Spirituality in the new world order. EXCEL International Journal of Multidisciplinary Management Studies, 2(1), 256-266.

Staines, G. L. (1980). Spillover versus compensation: A review of the literature on the relationship between work and nonwork. Human Relations,33(2), 111-129.
Stajkovic, A. D., Lee, D. \& Nyberg, A. J. (2009) Collective Efficacy, Group Potency, and Group Performance: Meta-Analyses of Their Relationships, and Test of a Mediation Model. Journal of Applied Psychology, 94 (3), 814-828.

Tierney, P., \& Farmer, S. M. (2002). Creative SelfEfficacy: Its Potential Antecedents and Relationship to Creative Performance. The Academy of Management Journal, 45(6), 1137-1148.

Triandis, H. C. (2001). Individualism-collectivism and personality. Journal of Personality, 69(6), 907-924.

Tuttle, Matthew D., "True North or Traveled Terrain? An Empirical Investigation of Authentic Leadership" (2009). Graduate School Theses and Dissertations.

Ullah Bukhari, Z. (2009). Key antecedents of organizational citizenship behavior (OCB) in the banking sector of Pakistan. International Journal of Business and Management, 3(12), 106-116.

Walsh, K., King, M., Jones, L., Tookman, A., \& Blizard, R. (2002). Spiritual beliefs may affect outcome of bereavement: prospective study. BMJ,324(7353), 1551-1559.

Wimsatt, A. M., \& Gassenheimer, J. B. (2000). The Moderating Effects of Cultural Context in Buyer-Seller Negotiation. The Journal of Personal Selling and Sales Management, 20(1), 1-9.

Zarafshani, K., Knobloch, N. A., \& Aghahi, H. (2008). General perceived self-efficacy of Iranian College of Agriculture students. Journal of International Agricultural and Extension Education, 15(1), 69-84.

Zhang, J. X., \& Schwarzer, R. (1995). Measuring optimistic self-beliefs: AChinese adaptation of the General Self-Efficacy Scale. Psychologia: An International Journal of Psychology in the Orient, 38(3), 174-181. 